\title{
ULTRASONOGRAFIA DE PIEL Y ANEXOS
}

\section{Dra. Carolina Whittle P, TM. Gina Baldassare P.}

Departamento de Imágenes. Servicio de Ecotomografía. Clínica Alemana de Santiago.

\begin{abstract}
High resolution ultrasound (US) produces an excellent definition of different skin layers and makes possible the study of different dermatological lesions. The anatomy and the normal skin ultrasound are presented. Size, nature and morphology of the lesions are well recognized, location and skin layers involved are depicted, and also the presence of blood vessels inside and around the tumor. US is an excellent guide of percutaneous biopsies.

The clinical and US presentations of the most frequent skin lesion are discussed: infundibular and trichilemmal cyst, lipoma, hemangioma, lymphangioma, pilomatrixoma, bursitis, foreign bodies granuloma and adenophaties.
\end{abstract}

Key words: Dermatology ultrasound, Dermatological pathology, Skin, Small parts, Ultrasound.

Resumen: La ecotomografía de alta resolución permite una buena demostración de las distintas capas de la piel permitiendo el estudio de las lesiones que la afectan. Se revisa la anatomía y representación ecotomográfica de la piel normal y patológica. El tamaño, características morfológicas, ubicación y capas de la piel comprometidas, así como su patrón vascular son bien estudiados con ultrasonografía, siendo posible en algunos casos llegar a un diagnóstico etiológico. Es también una buena herramienta para guiar estudios biopsicos. Se analizan las lesiones más frecuentes: quistes de la unidad pilosebácea, lipomas, hemangiomas, linfangiomas, pilomatrixomas, bursitis, granulomas por cuerpo extraños y adenopatías.

Palabras claves: Dermatología, Partes blandas, Patología dermatológica, Piel, Ultrasonografía.

\section{Introducción}

La piel es una extensa membrana que envuelve al hombre y le permite el contacto con el mundo exterior, a través de una superficie de

Whittle C, Baldassare G. Ultrasonografía de piel y anexos. Rev Chil Radiol 2004; 10: 81-88.

Correspondencia: Dra. Carolina Whittle P.

carolinaw@mi.cl aproximadamente $18.000 \mathrm{~cm}^{2}$. Las lesiones que la afectan son múltiples y variadas, en su mayoría de pequeño tamaño $0^{(1,8)}$.

La ultrasonografía (US) como método de diagnóstico permite detectar y registrar la energía reflectada desde las distintas interfases que se producen en el cuerpo al incidir el haz sonico. Este fenómeno puede proveer imágenes de alta resolución, bidimensionales, en escala de grises y permite además detectar la presencia de flujo sanguíneo y cuantificarlo(2). Se considera una herramienta médica versátil, de gran utilidad, cuyo rendimiento se optimiza con el uso de equipos de alta tecnología y operadores con adecuados conocimientos de los principios físicos y herramientas disponibles, en conjunto al dominio de la anatomía y patología del órgano a examinar. Es el único método de diagnóstico por imágenes capaz de obtener alta resolución espacial que alcanza a los 0,5 a $1,0 \mathrm{~mm}$, permitiendo conseguir imágenes de alta calidad de estructuras superficiales como la piel.

Es necesario en el estudio de piel utilizar transductores lineales, de alta frecuencia y de banda ancha. Lineales, para evitar la deformación geométrica de los planos superficiales y mejorar la resolución proximal; frecuencia alta en rango de 10 a $17 \mathrm{MHz}$, para aumentar la resolución axial y banda ancha para poder enfocar los planos superficiales y profundos (Figura 1).

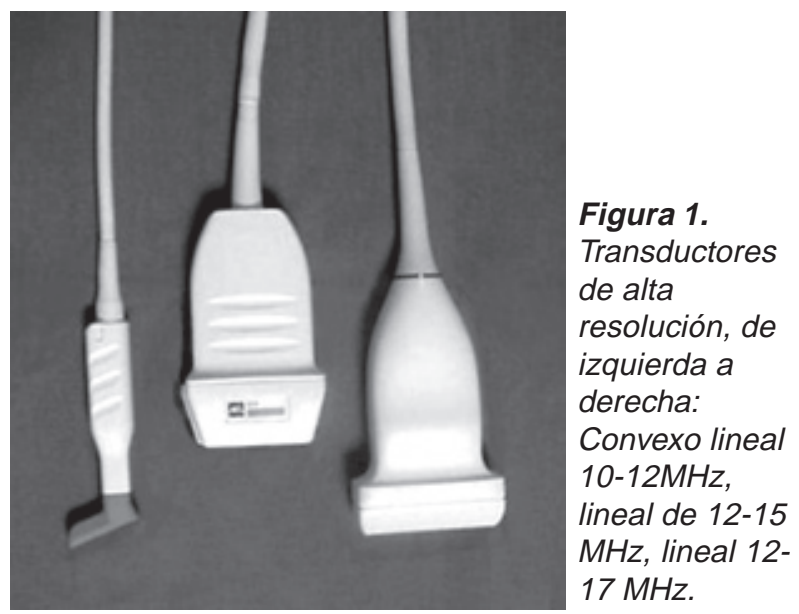


En el estudio de lesiones superficiales es necesario el uso de un molde preformado de gelatina o abundante gel dando un grosor no mayor a 0.5 $\mathrm{mm}$, para obtener un adecuado enfoque de las capas superficiales.

\section{Anatomía}

La piel es el órgano más extenso del cuerpo, recubre y reproduce todas sus eminencias y depresiones. El sentido del tacto esta asentado en ella. Tiene múltiples funciones entre las que destaca la inmunológica y la función barrera, que impide la entrada de sustancias u organismos del exterior y la pérdida desde el interior. Otras funciones, no menos importantes son: Filtro de la radiación ultravioleta, función reparadora de heridas, ulceras y daño celular, funciones vasculares nutritivas y reguladoras de temperatura, y la de extracción de residuos orgánicos, aparte de las funciones sensitivas o de comunicación.

Su espesor es variable, siendo más fina en párpados, pene, cara flexora de las articulaciones, y en el fondo de los grandes pliegues cutáneos, y más gruesa en la cara extensora de las articulaciones, regiones plantares y palmares expuestas a un mayor roce.

Esta compuesta por tres capas: a) Epidermis, b) Dermis que en conjunto con la primera conforman el cutis con un grosor de alrededor de $14 \mathrm{~mm}, \mathrm{c}$ ) Hipodermis o tejido graso subcutáneo (Figura 2 a). a. Epidermis: Es la parte más externa y está constituida por un epitelio escamoso que tiene un grosor de 0,05 a 1,5 $\mathrm{mm}$ y que es variable de acuerdo a la edad. Está formada por 4 capas y en ella podemos encontrar varios tipos celulares: queratinocitos, melanocitos, células de Langerhans, células de Merkel, células indeterminadas y células de Torkel. b. Dermis: Esta formada por una red de colágeno y fibras elásticas. Contiene también redes vasculares dispuestas paralelamente a la superficie cutánea y conectada entre sí por los vasos verticales. Su grosor oscila entre 0.5 y $3 \mathrm{~mm}$. En ella podemos encontrar: fibras colágenas, elásticas y reticulares, células como fibroblastos, mastocitos y macrófagos, elementos vasculares, neurales y anexos como pelos, glándulas ecrinas, apocrinas y sebáceas.

La dermis se divide en dos partes: la dermis papilar o superficial y la dermis reticular o media.

- La dermis papilar localizada por debajo de las papilas dérmicas es muy vascularizada y tiene fibras de reticulina.

- La dermis reticular es más rica en colágeno y fibras elásticas. El fibroblasto es la célula más abundante y tiene como misión la fabricación de los elementos fibrosos de la dermis, especialmente colágeno. Esta es una proteína que además del fibroblasto puede ser producida por otras células como el miofibroblasto, osteoclasto, etc. El colágeno no es homogéneo en todo el organismo, existen 13 tipos de acuerdo a su morfología, composición de aminoácidos y propiedades físicas. Las fibras elásticas son esenciales para las propiedades retráctiles de la piel y solo representan un $2-4 \%$ de los constituyentes de la dermis

c. Hipodermis: Es la capa más profunda de la piel. Está compuesta por una red de células de colágeno y grasa, que ayuda a conservar el calor corporal y protege el cuerpo contra lesiones dado que amortigua los impactos.

Anexos de la piel: Las estructuras anexas de la piel incluyen pelos, uñas, glándulas sebáceas, glándulas sudoríparas ecrinas y glándulas sudoríparas apocrinas.

Unidad folículo-sebáceo: Son prolongaciones córneas de origen epidérmico que existen en todo el cuerpo excepto en las regiones palmar, plantar, dorso, extremos dístales de manos y pies, además de algunas áreas genitales y labios. Ellos constan de folículo propiamente dicho, con vainas de pelo; glándulas sebáceas, músculo erector del folículo y en algunas regiones, de glándulas sudoríparas apocrinas (Figura 2 b, c).
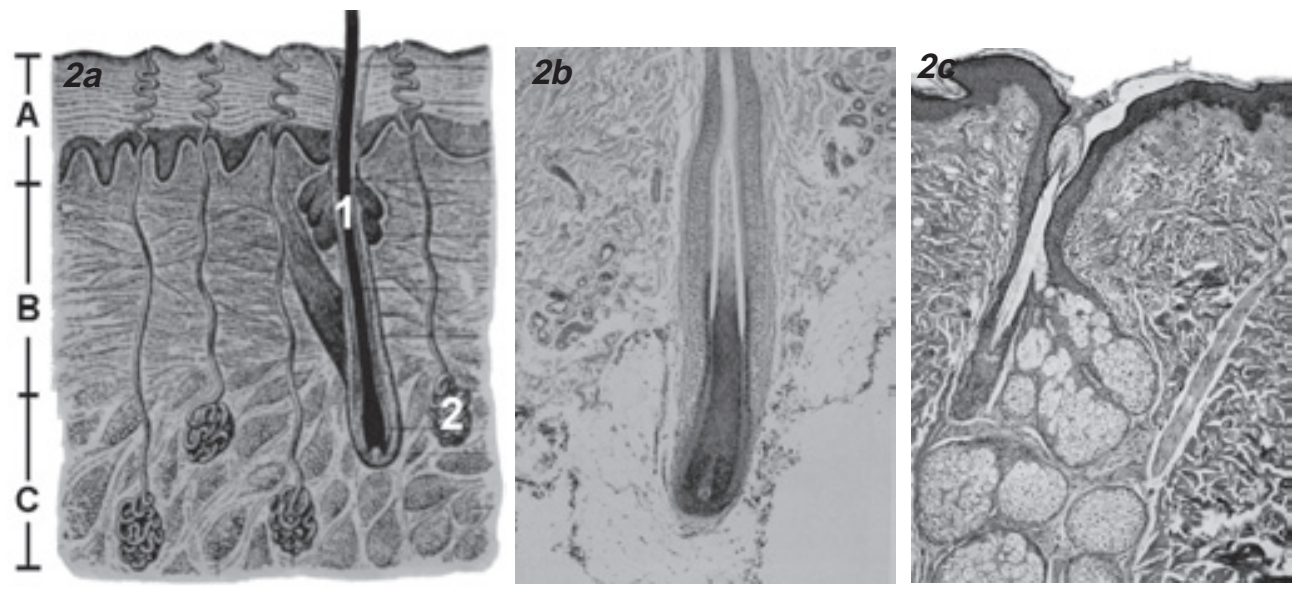

Figura 2 a-c. a: Anatomía de la piel (modificado de referencia 1). b: Folículo piloso. c: Unidad pilosebácea (microfotografías modificadas de referencia 8). A: Epidermis. B: Dermis.papilar C: Dermis reticular. 1: Unidad folículo-sebácea. 2: Glándulas sudoríparas ecrina. 
Glándulas sudoríparas (ecrinas): Secretan el sudor directamente en la piel y son numerosas en especial en región plantar y palmar. En la axila y regiones inguino-crurales son más voluminosas. Las de los conductos auditivos externos se denominan ceruminosas y secretan cerumen.

Glándulas sebáceas: Son estructuras arracimadas, que secretan sebo o materia sebácea, drenan al folículo piloso o directamente a la superficie cutánea.

\section{US: Anatomía, ventajas y desventajas}

La ecotomografía permite evaluar en forma adecuada la anatomía de la piel. Normalmente la epidermis corresponde a la interfase con el gel que se expresa como una línea ecogénica. La dermis se demuestra como una banda que al US mide aproximadamente 2-4 $\mathrm{mm}$., con un componente superficial hipoecogénico que corresponde a la dermis papilar y una porción profunda ecogénica que corresponde a la dermis reticular. La hipodermis o subcutáneo se representa como un tejido hipoecogénico con estrías lineales ecogénicas que representan las fibras que separan los lobulillos adiposos (Figura 3).
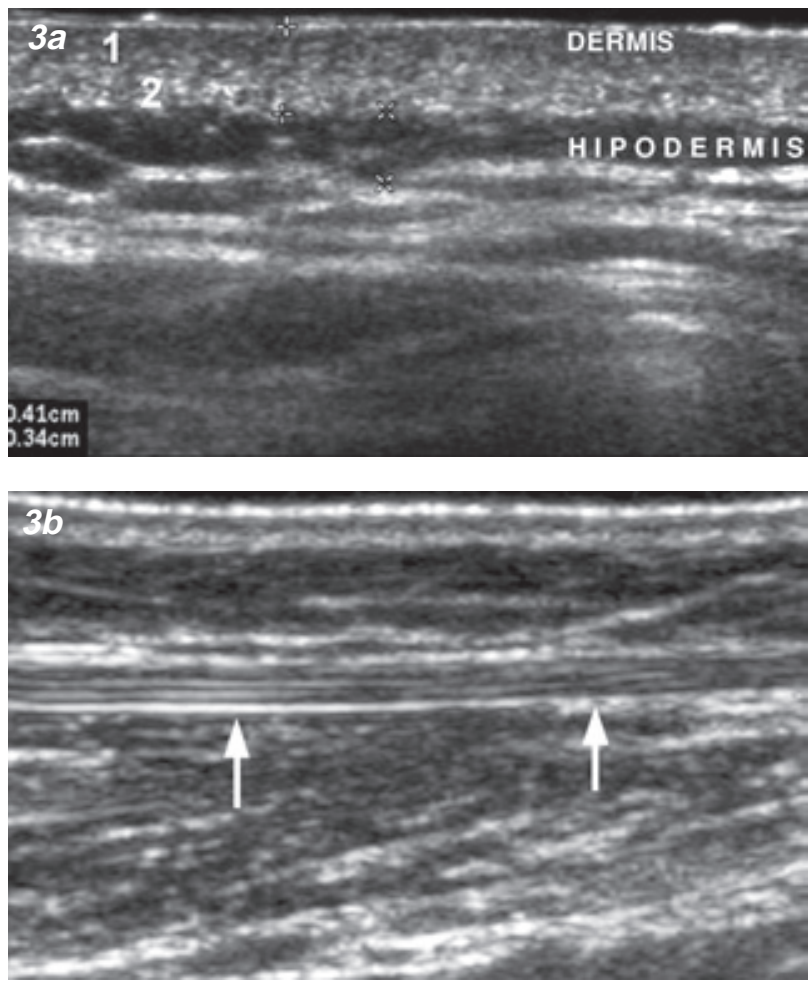

Figura 3 a,b. Ecotomografía de piel normal y sus capas a: Corte de piel a nivel de antebrazo dorsal destacando una hipodermis delgada. b: Corte en antebrazo palmar con subcutáneo más grueso, se marca tendón flexor con flechas. Se identifica dermis e hipodermis. 1: Dermis papilar. 2: Dermis reticular. Nótese en la hipodermis las finas imágenes lineales correspondiente a septos entre los lobulillos grasos.
El estudio ultrasonográfico de la patología dermatológica permite evaluar el tamaño y extensión de las lesiones, las capas comprometidas, la presencia de vascularización patológica con el uso de Doppler color y en algunos casos orienta a un diagnostico etiológico.

La demostración de las lesiones superficiales es de alta calidad, siendo la US un excelente método para guía de biopsias percutáneas dando la posibilidad de introducir la aguja en un plano próximo a la horizontal al transductor lo que mejora su visualización (Figura 4).

Sus principales desventajas son el ser un examen operador y equipo dependiente y que existen muchas lesiones que son inespecíficas y no pueden ser bien caracterizadas.

Analizaremos las lesiones que con mayor frecuencia afectan a la piel y sus anexos.

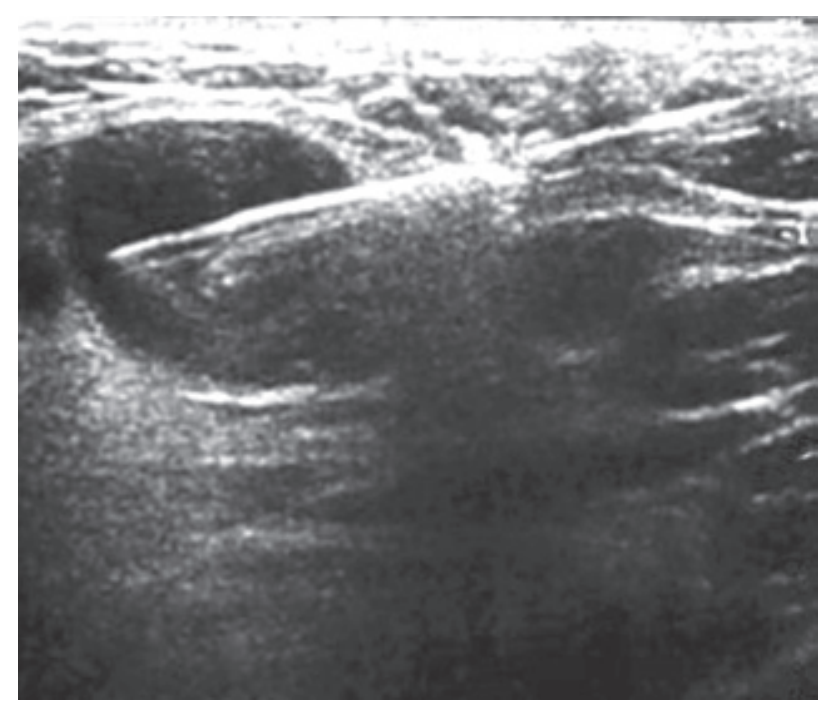

Figura 4. Biopsia percutánea bajo ecotomografía de nódulo sólido subcutáneo. La aguja se observa claramente como imagen lineal ecogénica.

1.- Quistes de los anexos epiteliales (Figura 5) 1 a. Quiste infundibular: La mayoría de los quistes infundibulares comienzan en la unidad pilosebácea, actualmente se denominan quistes de inclusión epidérmicos. En su mayoría son resultado de una ectasia quística progresiva del infundíbulo del folículo piloso. Son más frecuentes en cuello, tórax y cara; en especial en la región preauricular. Se asocian a acne y son más frecuentes en el sexo masculino en una relación 2:1.

Es un quiste solitario o múltiple de $3 \mathrm{~mm}$ a centímetros. Pueden tener un pequeño punto que marca su conexión a la epidermis. Generalmente no protruyen hacia la superficie. Tienen queratina y se pueden romper o supurar, dando reacción a cuerpo extraño con inflamación crónica constituyendo la paniculitis. 

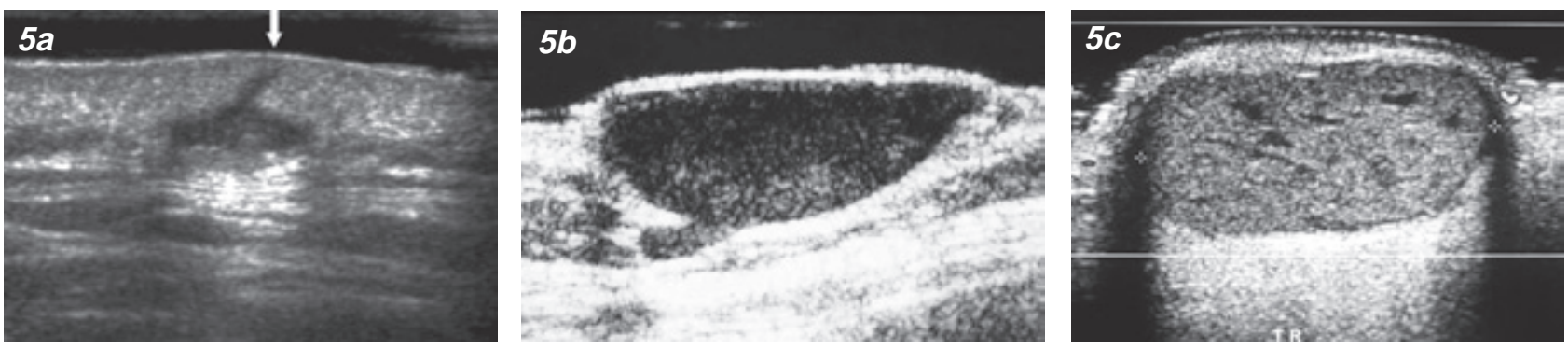

Figura 5 a-c. Quistes derivado de los anexos epiteliales. a: Se muestra un fino cuello que cruza la dermis hacia la superficie, hallazgo característico del quiste epidérmico (flecha). b: Quiste triqueminal. c: Doppler de amplitud demostrando ausencia de flujo en la lesión y la presencia en su periferia.

Algunos de estos quistes pueden tener un componente principalmente sebáceo y se distribuyen principalmente en tórax, dorso, axila y entrepierna. Son más comunes en la pubertad y estos son más raros que se infecten ${ }^{(3,4)}$.

1 b. Quiste triquilemal: Es el segundo quiste en orden de frecuencia y constituyen el $15 \%$ de las intervenciones quirúrgicas en dermatología. Se localizan frecuentemente en cuero cabelludo. A la palpación es suave, firme y móvil. Más común en mujeres, no se inflaman y tampoco presentan comunicación con la epidermis. Existe una variedad proliferante, multilobulada, que se ve en mujeres mayores de 60 años con alopecia.

\section{2.- Lipomas}

Es el tumor benigno de partes blandas mas frecuente y está compuesto por tejido adiposo maduro Es de crecimiento lento, de ubicación superficial (Figura 6) o profundo intramuscular (Figura 7) o intraoseo. En general es asintomático, pero en $25 \%$ de los $\operatorname{casos}^{(3)}$ puede ser sensible o dar dolor por la compresión de nervios periféricos.

El tejido adiposo puede asociarse a otros elementos mesenquimáticos constituyendo fibrolipomas, miolipomas, angiolipomas ${ }^{(3-5)}$.

A la US tiene varias formas de presentación, puede ser muy hipoecogénico, similar al tejido adiposo subcutáneo adyacente y si la cápsula es muy fina puede ser difícil de diferenciarlo de este. Pueden presentar septos ecogénicos que corresponder a tejido fibroso entre los lobulillos adiposos. A veces son muy ecogénicos y homogéneos, en especial los de pequeño tamaño y en otros casos son heterogéneos con presencia de septos ecogénicos. Es una lesión hipovascular al Doppler color.

\section{3.- Hemangiomas}

Es una lesión frecuente, según algunas series constituyen el $7.6 \%$ de todos los tumores benignos de partes blandas ${ }^{(3)}$. Es más frecuente en las primeras décadas de la vida y en el sexo femenino.

Están compuestos por estructuras vasculares, pero también pueden contener grasa, músculo liso, tejido fibroso, hueso y trombos. Generalmente no están presentes al nacimiento a diferencia de las malformaciones vasculares. En su evolución presentan crecimiento y tardíamente regresión con menor número de vasos visibles y aumento de la ecogenicidad por involución adiposa.

Se presenta como una masa de partes blandas muy vascularizada identificándose al Doppler color venas y arterias de baja resistencia pudiéndose demostrar los vasos que alimentan la lesión y su calibre (Figura 8). Son de predominio ecogénico, pero puede ser hipoecogénico o mixto en caso de lesiones cavernosas (Figura 9).

Son de ubicación superficial (Figura 10) o profunda: intramusculares (Figura 11) o viscerales. En caso de compromiso muscular puede ser doloroso con el ejercicio ${ }^{(3,4)}$. En ocasiones pueden presentar calcificaciones que corresponden a flebólitos (Figura $11 \mathrm{c})$.

\section{4.- Malformación vascular linfática (Linfangiomas)}

Son tumores benignos poco frecuentes. Clínicamente están presentes al nacimiento o pueden expresarse durante la lactancia o infancia. Están compuestos por tejido linfático secuestrado no comunicado, delineado por tejido endotelial. Pueden ser uni o multiloculados, capilares, cavernosos o higromas quísticos.

Se presentan como lesiones quísticas, de pared fina, con septos de grosor variable, en los cuales pueden existir vasos sanguíneos ${ }^{(3,4)}$. Las lesiones tienden a ser extensas con compromiso subcutáneo y profundo (Figura 12). A la palpación son blandos y la epidermis se observa discretamente solevantada por la lesión.

\section{5.- Pilomatrixomas}

Estas lesiones tienen su mayor incidencia en menores de 15 años, con una edad media de 7.5 años. Hay una discreta predominancia en el sexo femenino 1,5:1. El $90 \%$ se ubican en cara, cuello, extremidad superior. Su tamaño es menor a $3 \mathrm{~cm}$., y el promedio es de alrededor de $8 \mathrm{~mm}$. Son de crecimiento lento. En $84 \%$ de los casos existen calcificaciones ${ }^{(6)}$. AI US son lesiones de predominio ovalado, de contornos 


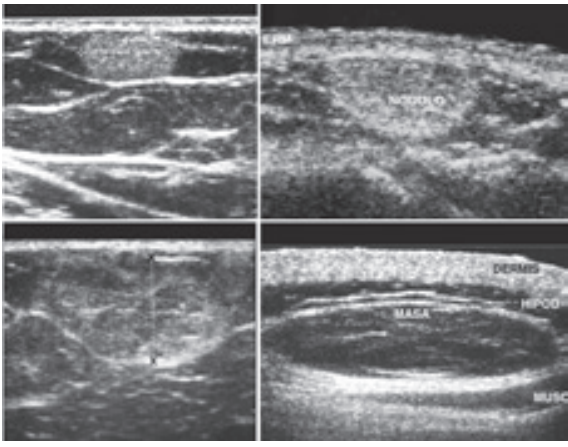

Figura 6 a-d. Lipomas superficiales subcutáneos. Diferentes formas de presentación. a: Ecogénico homogéneo.

b: Ecogénico con finos septos. c:

Heterogéneo con focos hiper e hipoecogénicos. d: Hipoecogénico con septos ecogénicos.

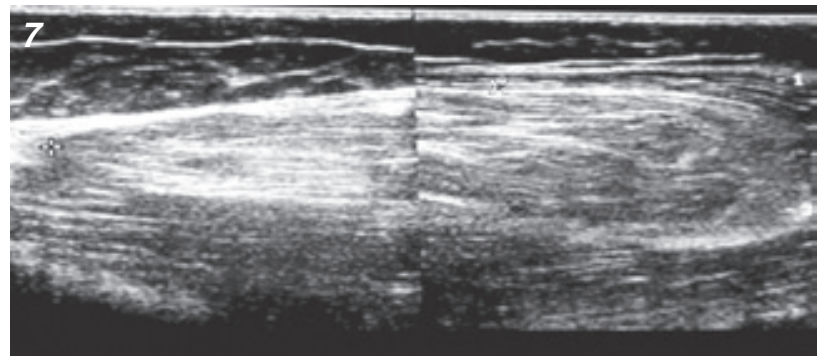

Figura 7. Imagen compuesta demostrando un lipoma profundo intramuscular.
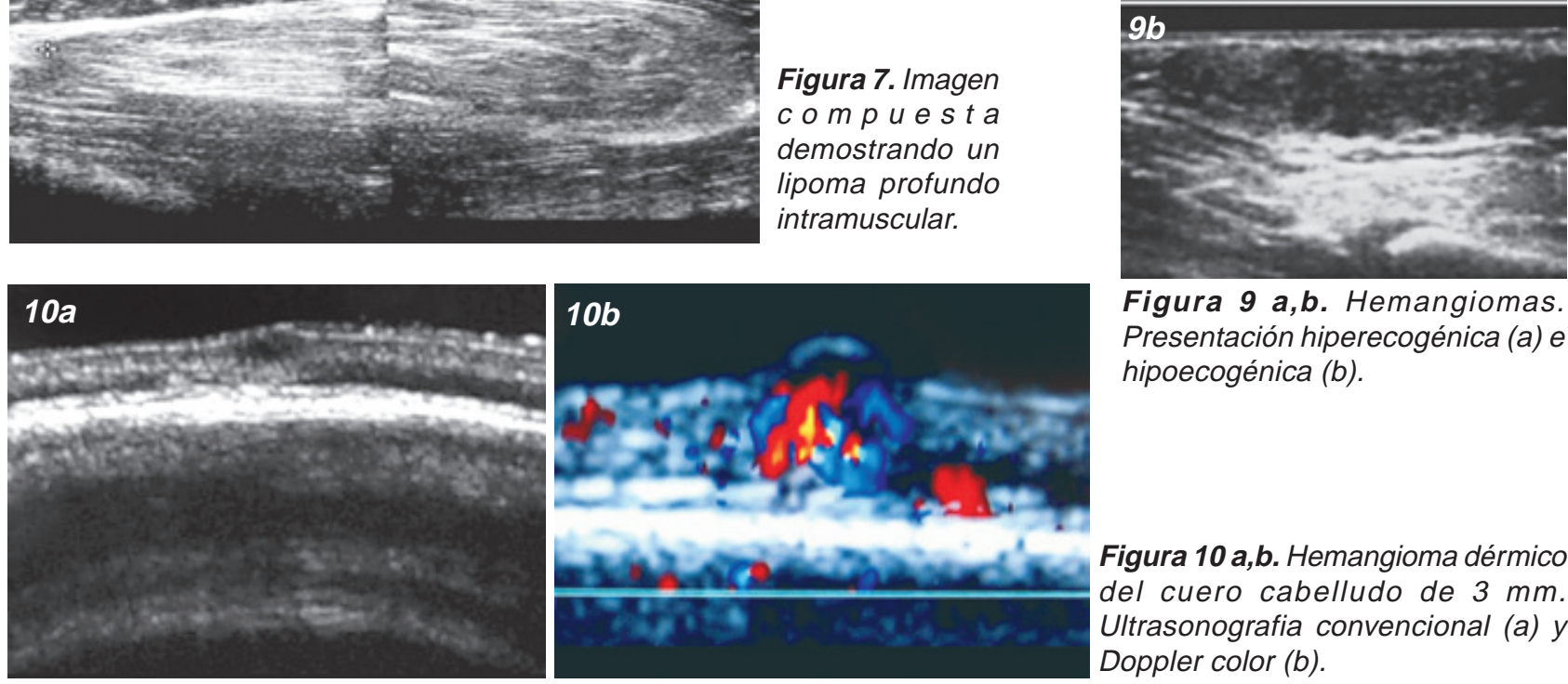

Figura 9 a,b. Hemangiomas. Presentación hiperecogénica (a) e hipoecogénica (b).

Figura 10 a,b. Hemangioma dérmico del cuero cabelludo de $3 \mathrm{~mm}$. Ultrasonografia convencional (a) y Doppler color (b).

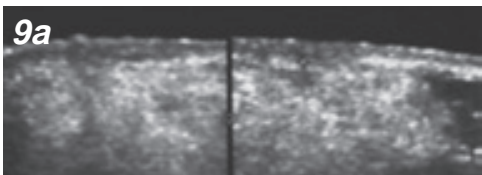

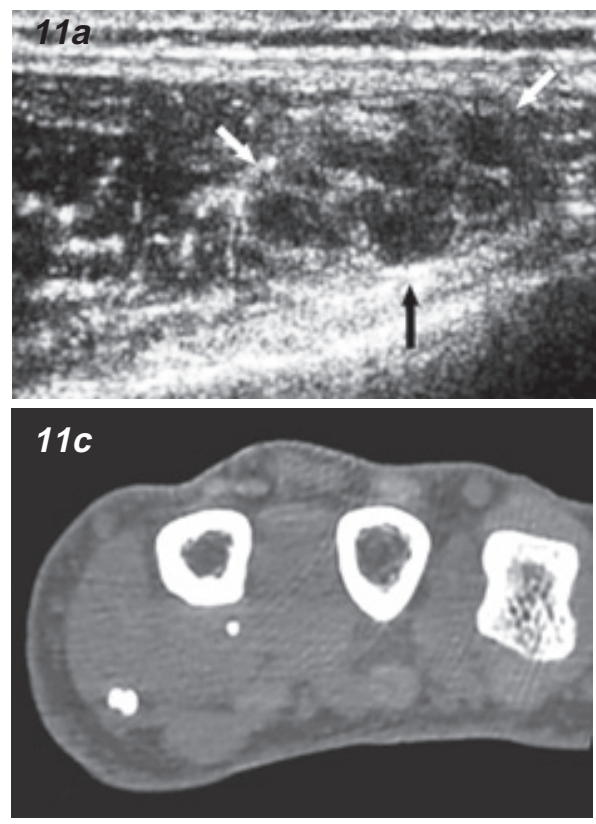
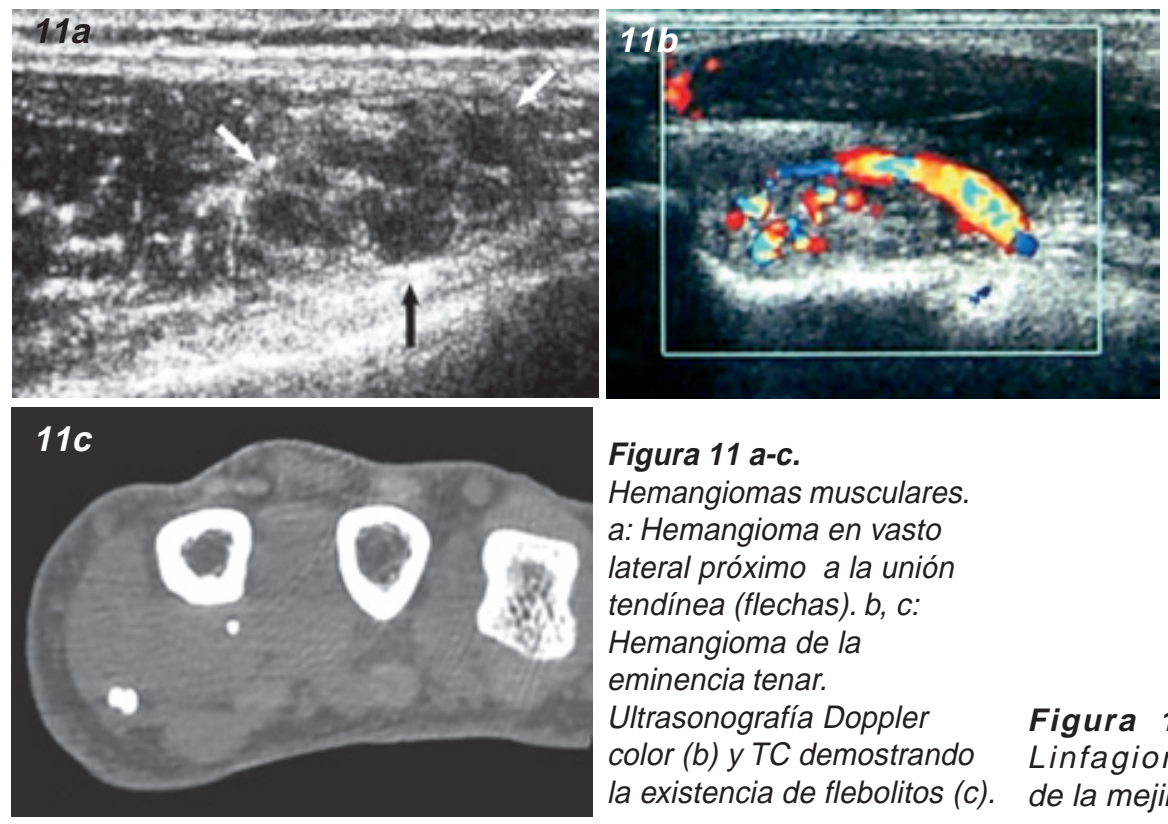

Figura 11 a-c.

Hemangiomas musculares. a: Hemangioma en vasto lateral próximo a la unión tendínea (flechas). $b, c$ Hemangioma de la eminencia tenar. Ultrasonografía Doppler color (b) y TC demostrando la existencia de flebolitos (c).
Figura 12. Linfagioma de la mejilla.

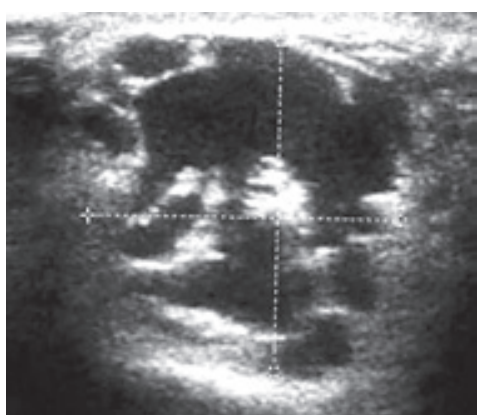


regulares, con halo periférico y sombra acústica hacia distal dependiendo de la calcificación (Figura 13). En algunos casos presentan signos inflamatorios regionales.

Existe una forma maligna: Carcinoma pilomatrixoma, en hombres de la tercera edad.

\section{6.- Bursitis}

Corresponde a una inflamación de la bursa que puede ser de origen: a) Post-traumático, generalmente hemorrágicas con ecos en su interior. b) Por microtraumatismo, secundaria a fricción repetida. c) Inflamatorias. d) Infecciosas. Son de ubicación superficial o profunda, la más frecuente es la subcutánea.

Son hipoecogénicas, con bolsillos líquidos y tabiques de grosor variables y con frecuencia presentan aumento de la ecogenicidad del tejido adiposo adyacente e hiperemia ${ }^{(5)}$ (Figura 14).

Los lugares de presentación más frecuentes son: pre-rotulianas, olecraniana, retroaquiliana donde es llamada enfermedad de Haglund.

\section{7.- Granulomas a cuerpo extraño}

Los cuerpos extraños solo se ven fácilmente a rayos $\mathrm{X}$ si son radioopacos, pero el $85 \%$ de ellos son radiolúcidos. El US demuestra fácilmente todos los cuerpos extraños. Se pueden ver como una imagen lineal ecogénica o como dos líneas en forma
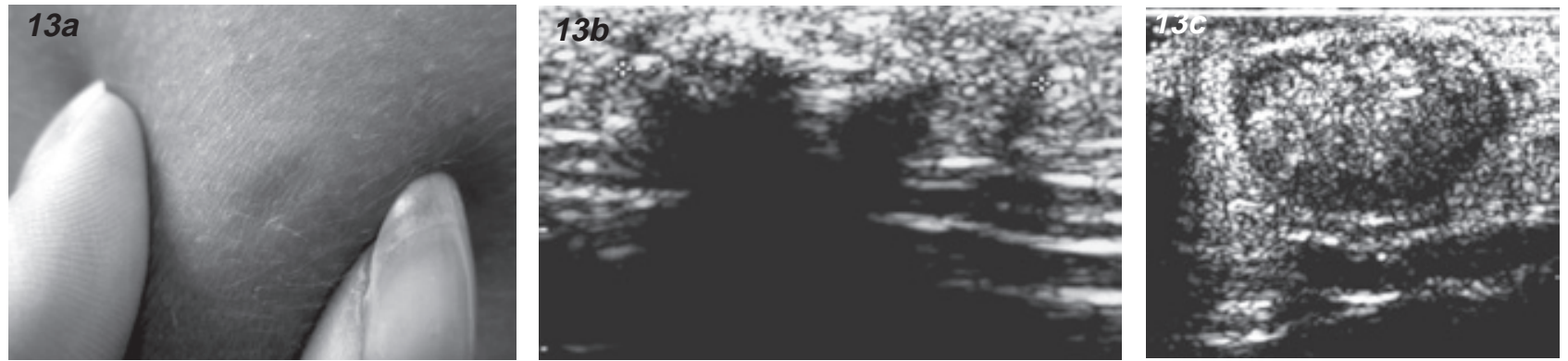

Figura 13 a-c. Pilomatrixoma presentación clínica (a) y ecográfica destacando la calcificación (b) y el halo periférico hipoecogenico (c).

Figura 14 a,b. Bursitis olecraniana. Paciente con aumento de volumen en la región dorsal de codo (a). Ultrasonografía demostrando la bursa inflamada (b). de riel sin artefacto posterior en los de origen vegetal (Figura 15), y con artefactos posterior en caso de vidrio, metal, piedra o polímeros (Figura 16), los cuales presentan reverberación o sombra acústica. Su ubicación más frecuente es en manos y pies. En etapa tardía pueden estar rodeados por una reacción inflamatoria hipoecogénica con las características de una granuloma circunscrito o pueden asociarse a infección secundaria, con absceso de partes blandas, tenosinovitis u osteitis ${ }^{(7,5)}$.

\section{8.- Adenopatías}

Los ganglios clásicamente son hipoecogénicos, ovalados con un centro hiperecogénico (Figura 17). Al Doppler color presentan estructuras vasculares de distribución hiliar. Los de ubicación superficial, subcutánea se hacen fácilmente palpables y son un motivo de consulta frecuente. Los cambios detectables al US son: aumento de tamaño, cambios de la estructura, cambios inflamatorios con extensión a la grasa perinodal(5).

\section{9.- Lesiones malignas}

El ultrasonido permite determinar las características morfológicas de una lesión y su extensión en profundidad, pudiendo medirse la penetración a planos profundos en $\mathrm{mm}$. También muestra los planos comprometidos. Esto tiene un alto valor predictivo y terapéutico, en especial en casos de melanoma (Figura 18).
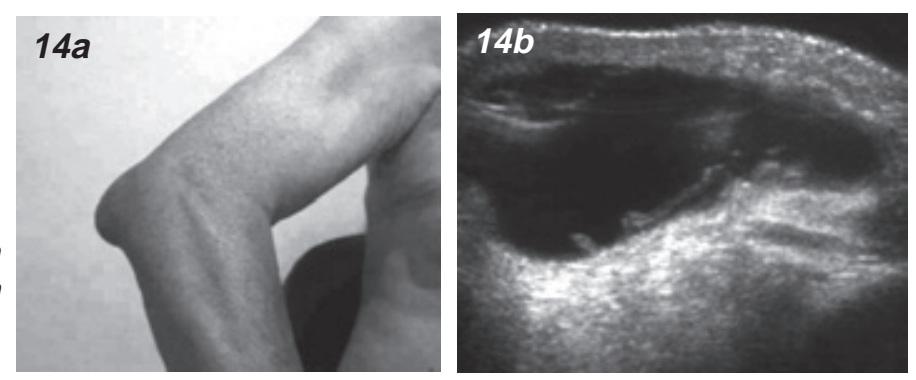
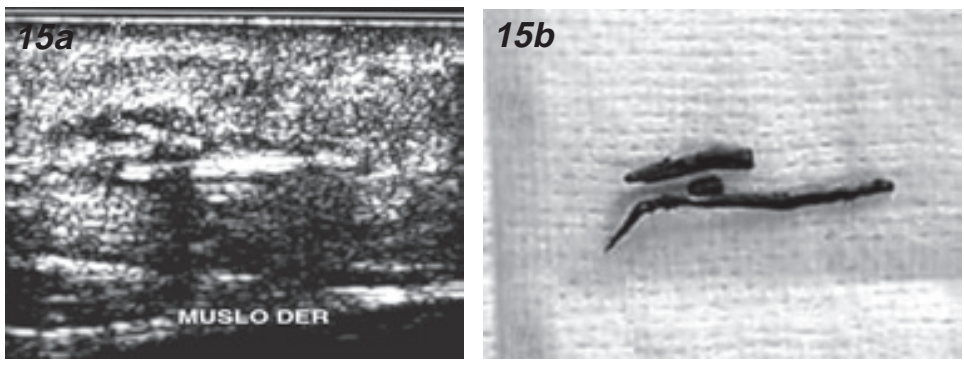

Figura 15 a,b. Cuerpo extraño vegetal con dos fragmentos en muslo. Ultrasonografía (a).

Espécimen quirúrgico (b). 


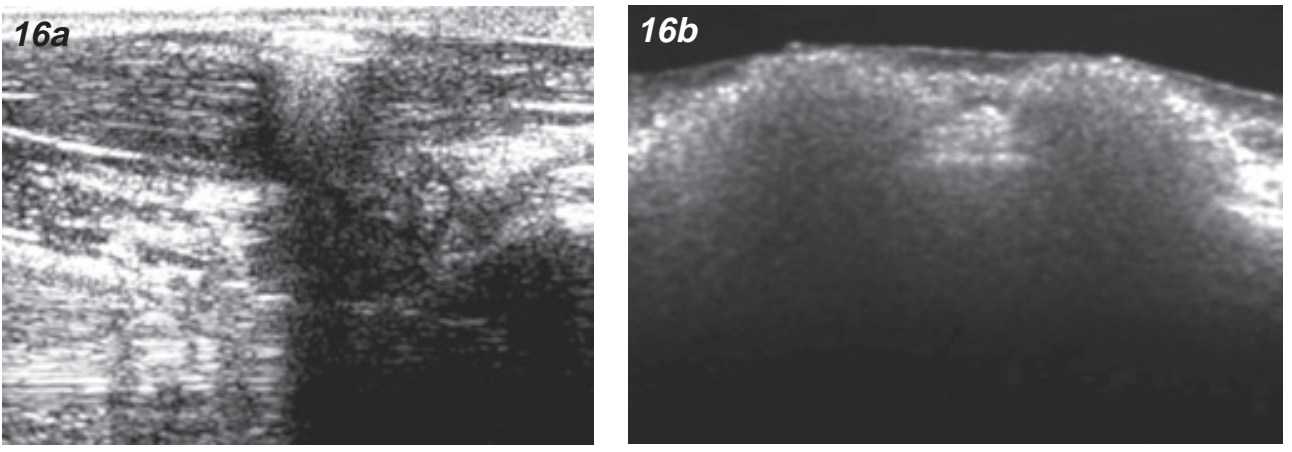

Figura 16 a,b. a: Cuerpo extraño correspondiente a trozo de vidrio en la mano. b: Depósitos de biopolímeros o silicona facial.

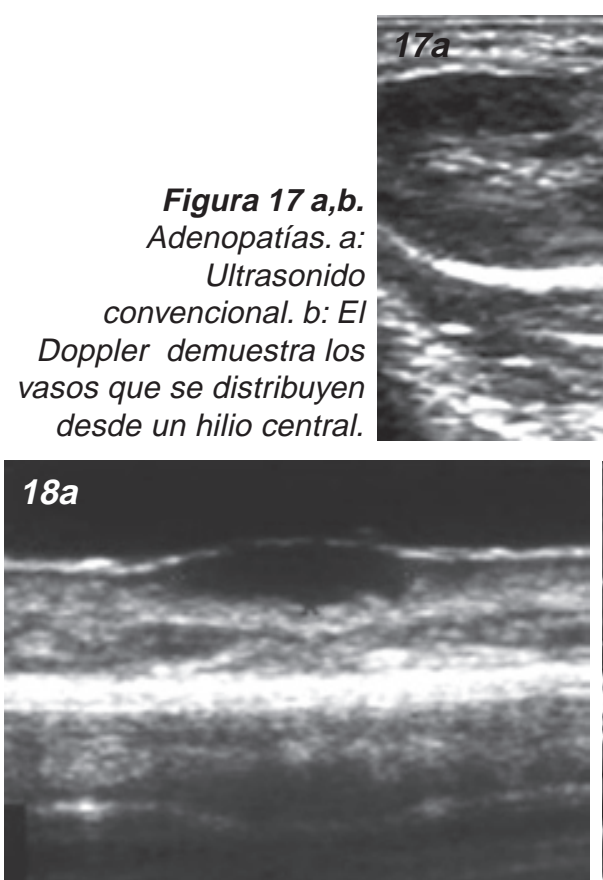

\section{Conclusión}

La ecotomografía de alta resolución permite una excelente evaluación de las lesiones de partes blandas, incluidas las lesiones dermatológicas. Sin embargo, se trata de un campo nuevo en el que se necesita de equipos adecuados con transductores, de a lo menos $12 \mathrm{MHz}$. Es necesario un buen conocimiento de la anatomía ultrasonográfica de las capas cutáneas y de su patología.

\section{Bibliografía}

1. Testut L, Latarjet A. Tratado de Anatomía Humana. Libro VIII. "rganos de los Sentidos. Salvat Editores. Barcelona. 1976; 447-487.

2. Rumack C, Wilson S, Charboneau J. Diagnostic Ultrasound. Year Book, Inc. Second Edition. Mosby.

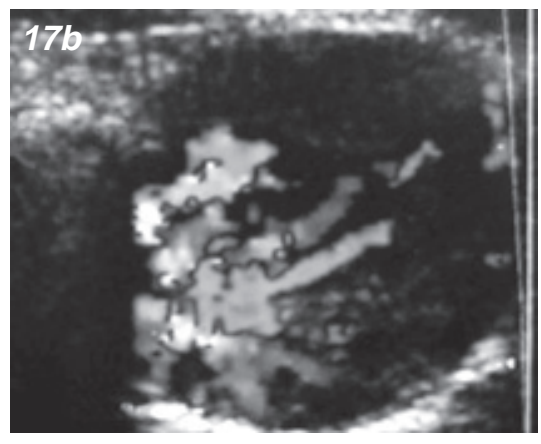

Figura 18 a,b. Diferentes grados de penetración cutánea de neoplasias. a: Lesión que compromete el dermis. $b$ : Lesión infiltrante con compromiso del subcutáneo.

1998; 2: 3-33.

3. Kransdorf M., Murphey M. Imaging of soft tissues tumors. W.B. Saunders Company. 1997; 37-56, 57-101, 103-43, 209-12, 410-17.

4. Weedon D, Skin Pathology. Marban Editores. 2002.; Vol I y II. Pag 425-454, 787-793, 827-846.

5. Brasseur J,Tardieu M. Êcographie du système locomoteur. Masson S.A. $1999 ; 70-84$.

6. Whittle C, Martínez W, Baldassare G, Smoje G, Bolte K, Busel D, González S. Pilomatrixoma: diagnóstico ecotomográfico. Rev Med Chil 2003; 131: 735-740.

7. Whittle C, Gonzalez P, Horvath E, Niedmann JP, Baldassare G, Seguel S, Mac Kinnon J. Detección y caracterización por ultrasonido de cuerpos extraños de partes blandas. Rev Med Chil 2000; 128: 419-24.

8. Maize JC. Cutaneous pathology. Churchill Livingstone. 1 ed. US. 1998.

\section{CONGRESO CHILENO DE MEDICINA NUCLEAR 4, 5 Y 6 NOVIEMBRE 2004 SANTIAGO CHILE}

